\title{
Game Graph and Formats Approach for Mixlingual Data Ontology for Geological and Marketing Tasks
}

\author{
Ekaterina S. Skornyakova*a, \\ Dmitry V. Lichargin ${ }^{\mathrm{a}, \mathrm{b}}$ and Pavel V. Polunian ${ }^{\mathrm{a}, \mathrm{b}}$ \\ a Siberian Federal University \\ Krasnoyarsk, Russian Federation \\ ${ }^{b}$ Information Estimation Institute \\ Krasnoyarsk, Russian Federation
}

\begin{abstract}
The paper introduces a new concept - trans-forest. A forest is a complex of additional connected trees. The skeleton of the graph is the basic multi-hierarchy. Subjects and "forces" are sources of moves on the playing field of the trans-forest based on the rules of the generative grammars of Montague. Each move of all generative grammars is synchronized with the meta-generative grammar - the "daemon of time". Each turn over a trans-forest can be done by moving the present marker on the time tree to the "Next" position. Particular attention is paid to the format tree and transconnections between trees and its levels, since it is the format tree that determines human behavior in certain situations. An algorithm of evolutionarily justified expansions is proposed, the purpose of which is to ensure well-being for the subject himself and other subjects. The proposed trans-forest model is intended for modeling educational, language IT marketing, geological and other situations from the point of view of graph theory and game theory.
\end{abstract}

Keywords: game theory, graph theory, trans-tree, trans-forest, generative grammar. 


\title{
Игровой граф и форматный подход
}

\section{для смешанно-языковой онтологии данных}

\section{в задачах геологии и маркетинга}

\author{
Е.С. Скорнякова ${ }^{a}$, \\ Д.В. Личаргин ${ }^{\mathrm{a}, \boldsymbol{0}}$, П.В. Полуян ${ }^{\mathrm{a}, \tilde{0}}$ \\ ${ }^{a}$ Сибирский федеральный университет \\ Российская Федераиия, Красноярск \\ ${ }^{6}$ Институт оченки информащии \\ Российская Федераиия, Красноярск
}

\begin{abstract}
Аннотация. В работе вводится новое понятие - «транслес» (trans-forest). Лес является совокупностью деревьев, связанных дополнительно. Остов графа составляет базовая мультииерархия. Субъекты и «силы» являются на игровом поле транслеса источниками ходов на основе правил порождающих грамматик Монтегю. Каждый ход всех порождающих грамматик синхронизирован с метапорождающей грамматикой - «демоном времени». Каждый ход над транслесом можно сделать с передвижкой маркера настоящего на дереве времени на позицию «Следующий». Особенно внимание уделяется дереву форматов и транссвязям между деревьями и его уровнями, поскольку именно дерево форматов определяет поведение человека в тех или иных ситуациях. Предлагается алгоритм эволюционно оправданных экспансий, цель которого обеспечение благополучия для самого субъекта и других субъектов. Предложенная модель транслеса предназначена для моделирования учебных, языковых IT-маркетинговых, геологических и иных ситуаций с точки зрения теории графов и теории игр.
\end{abstract}

Ключевые слова: теория игр, теория графов, трансдерево, транслес, порождающая грамматика.

Цитирование: Скорнякова, Е.С. Игровой граф и форматный подход для смешанно-языковой онтологии данных в задачах геологии и маркетинга / Е. С. Скорнякова, Д. В. Личаргин, П. В. Полуян // Журн. Сиб. федер. ун-та. Техника и технологии, 2021, 14(2). С. 252-259. DOI: 10.17516/1999-494X-0306

\section{Введение}

Вопрос о единой философско-математической модели мира ставился давно. И системный анализ является далеко не единственным подходом на пересечении философии и математики, в частности дискретной математики.

Первыми работами, которые были связаны с философией математики, стали труды древних философов, особенно греческих. Они интересовались началом мира и природой чисел, вводимых человеком, они первыми осознали относительность простого и сложного.

Одним из первых вопрос о моделировании игровых миров поставил, безусловно, Лейбниц. Однако научные исследования стали возможными лишь во второй половине XX века, когда возникла необходимость управлять быстро возрастающей сложностью создаваемых артефактов, в особенности программным обеспечением. Современная теория возникла из кибернетики Н. Винера, общей теории систем JI. Берталанфи и теории динамических систем, восходящей к И. Ньютону и А. Пуанкаре. С начала 1950-х годов в разработке этой теории деятельное участие принимают специалисты корпорации RAND, созданной для перспективных исследований в сфере компьютинга. 
Изучение этой проблемы в России осуществляется чаще всего под эгидой синергетики, в рамках которой работают известные отечественные философы и исследователи: В.И. Аршинов, В.Г. Буданов, И.С. Добронравова, К.Х. Делокаров, Д. И. Трубецков, В. В. Василькова, Д.С. Чернавский, В.В. Тарасенко, Р.Г. Баранцев, В.А. Шупер, В.П. Визгин, В.Г. Пушкин, В.С. Егоров, Н.С. Автономова, А.И. Алешин, И.А. Акчурин, М.К. Петров, И.С. Алексеев, А.А. Ахундов, А.А. Воронин, В.В. Налимов, Ф.И. Гиренок, В.А. Лекторский, Ј.А. Микешина, А.А. Андронов, Л. Левкович-Маслюк, П.П. Гайденко, В.С. Степин, С. С. Хоружий, Б. Г. Юлина, М. А. Розов, В.П. Филатов， В.Н. Порус， В.И. Моисеев， В.С. Швырев， В.И. Арнольд， А.В. Гапонов-Грехов, Г.К. Вороновский, Н.М. Амосов, Т.С. Ахромеева, Б.Б. Кадомцев, С.П. Капица, Ю.А. Данилов, К.В. Махотило, А.П. Ершов， О.Е. Баксанский， Ю.Л. Климонтович， С.Н. Петрашев， Г.Г. Малинецкий, А.П. Руденко, В.М. Глушков, Г.Е. Цейтлин, С.А. Сергеев, Е.Л. Ющенко, А.Н. Горбань, А.С. Дмитриев, Г.М. Идлис, Г.Р. Громов, Л.О. Мандельштам, В.Г. Редько, С.Э. Хайкин, С.П. Курдюмов, С.Е. Дромашко, Ю. И. Манин, А.Н. Шарковский, Г.Ю. Ризниченко, Р.Г. Хлебопрос, Ю. Л. Романовский, С. В. Мейен, Н.Н. Моисеев, А. Б. Потапов, А. М. Хазен, Г. А. Меерович.

В этой сфере науки работают многие зарубежные исследователи: С. Бир, Г. Хакен, Д. Роуз, К. Майнцер， Э. Ласло， П. Прузинкевич， В.Г. Тим， С. Кауфман， И. Пригожин， Г. Бюржель, Ф. Вучетич, В. Басиос, И. Антонеу, Г. Патти, С. Вольфрам, Г. Шефер, П. Бентли, М. Биркхард, Р. Брукс, Ф. Варела, Р. Вайтеккер, Н. Гесслер, Г. Николис, К. Гилман, Д. Энтони, К. Мур, Д. Микулески, Д. Чамберс, И. Стюарт, К. Нихейнив, К. Лэнгтон, К. Энди, М. Червински, Т. Нагель, Х.-О.Пайтаген, Р. Роузен, Ю. Кэнада, К. Лукас, П. Конвей, К. Стивене, У. Провост, Т. Янг, Дж. фон Нейман, Г. Демерси, Э. Приме, Я. Бар-Ям, П. Тагерд, В. Турчин, Д. Фолк, Р. Эшби, Ф. Хейлиген, А. Линденмайер, К. Эмич, Б. Смит, П. Вацлавик, М. Боден, П. Кнапп, С. Пайперт, В. Димитров, С. Сандерс, Э. Брюс, М. Чандлер, Д. Р. Чи, М. Хаим, Х. Прайс, Д. Вольперт, С. Улам, Л.М. Рош, Г. Саймон, Г. Чейтин, К. Шелли, Р.Х. Абрахам, У. Матурана, Д. Уотсон, Д. Касти, А. Онар, Г. Одум, Ф. Д. Абрахам, Д. Кэмпбелл.

\section{Игровое поле}

С точки зрения философии графовое поле игры разделено на логические секторы:

1) дерево (иерархия) форматов, дающее возможность выбора из подхода к деятельностнопознавательной игре субъектов:

a) личностный (темперамент (холерик, сангвиник, меланхолик, флегматик), привычки, временной формат (ночью - сон, утром - зарядка);

б) ситуативный (правила этикета);

в) социальные роли;

2) дерево (иерархия) понятий на основании тех или иных критериев;

3) иерархия времени, синхронизированная по ходам с ходом игры;

4) дерево (иерархия) игрового поля (например, «мир-страна-регион»);

5) отдельно вводится уровень иррационального субъекта, аппроксимируемого в модели, как граф модели всего мира, усвоенного некой умозрительной, предполагаемой нейросетью субъекта;

6) просубъектный уровень некой материальной подложки субъектов, алгоритмические принципы поведения моделируемого мира, действующие как порождающие грамматики в роли неких сил природы, или просто «сил». 
Деревья (иерархии) 1-2 назовем метафизическими.

Данный граф представляет собой остов игрового поля разных порождающих грамматик. Причем человек, как наблюдатель, может вмешиваться в модель и осуществлять свой иррациональный выбор из вариантов, допускаемых генерацией выбора случайных правил порождающих грамматик «ассистированная человеком генерация» («НAG»).

Ряд деревьев адресуется на граф-доску как фишки игры, это будут:

1) личность (субъект, как игровая фишка);

2) алгоритм глубины-действия-познания-рефлексии-...;

3) предмет, над которым осуществляются манипуляции.

В результате, граф-игра имеет три обобщенных раздела:

1) абстрактные объекты (критерии и понятийные единицы);

2) игровое поле;

3) деятели (actors) порождающих грамматик (субъекты и «силы» преобразований порождающих грамматик - гравитация, эффект трения и др.).

Субъекты и «силы» являются на игровом поле транслеса источниками ходов на основе правил порождающих грамматик Монтегю [1]. Моделируют игры разных форм массового сознания: научной, обиходной, эстетической и пр. В этой работе данная модель предлагается для геологической области.

Для эффективной работы с игровым графом требуется понятие - «транссвязь», то есть связь одного дерева или уровня дерева, адресуемая на другой уровень или на другое дерево. Транссвязи определенных типов могут быть запрещены правилами игр определенного типа.

\section{Простые предложения и программный код}

Объектно-ориентированная парадигма (ООП) лучше всего подходит для выражения зависимостей признаков каких-либо предметов и действий, которые можно совершать над предметами или с помощью них. Предложения вроде «Эхолокатор функционирует» может иметь следующее отражение в программном коде:

eholokator.funktsioniruet();

Применяя текстокодовую порождающую грамматику, программа порождает из программного кода предложение или предложения. Например, в вышеописанном фрагменте кода eholokator - объект, представитель какого-либо класса, способный совершать какие-либо действия (член предложения - подлежащее, с точки зрения семасиологической прагматики actor). Метод funktsioniruet - глагол, действие или набор действий, которые может выполнить представитель класса (член предложения - сказуемое, action).

Набор правил порождающих грамматик конкретизируемого пространственно-временного формата для модификации объекта представлен ниже:

Actor $>$ «Oborudovaniye.»| Subject $>$ «оборудование»

«Oborudovaniye.»> «Eholokator.»| «оборудование»> «эхолокатор»

«Oborudovaniye.» > «GeneratorVibratsii.»| «оборудование»> «генератор вибраций»

«Oborudovaniye.» > «IzmeritelnyiPribor.»| «оборудование» > «измерительный прибор»

Action $>$ funktsioniruet() $\mid$ Verb $>$ «работает» 
funktsioniruet() > «rejimOjidaniya()»| «работает» > «работает в режиме ожидания»

funktsioniruet() > «rejimSkanirovaniya()»| «работает» > «работает в режиме сканирования»

Возможные предложения: «Эхолокатор работает в режиме ожидания», «Генератор вибрации работает в режиме ожидания» и т. д. Эти и другие предложения генерируются в этой идеологии либо в виде текста, либо в виде кода (рис. 1, рис. 2), в результате чего классификация форматов включает те или иные объекты текстокода, представленного в форме

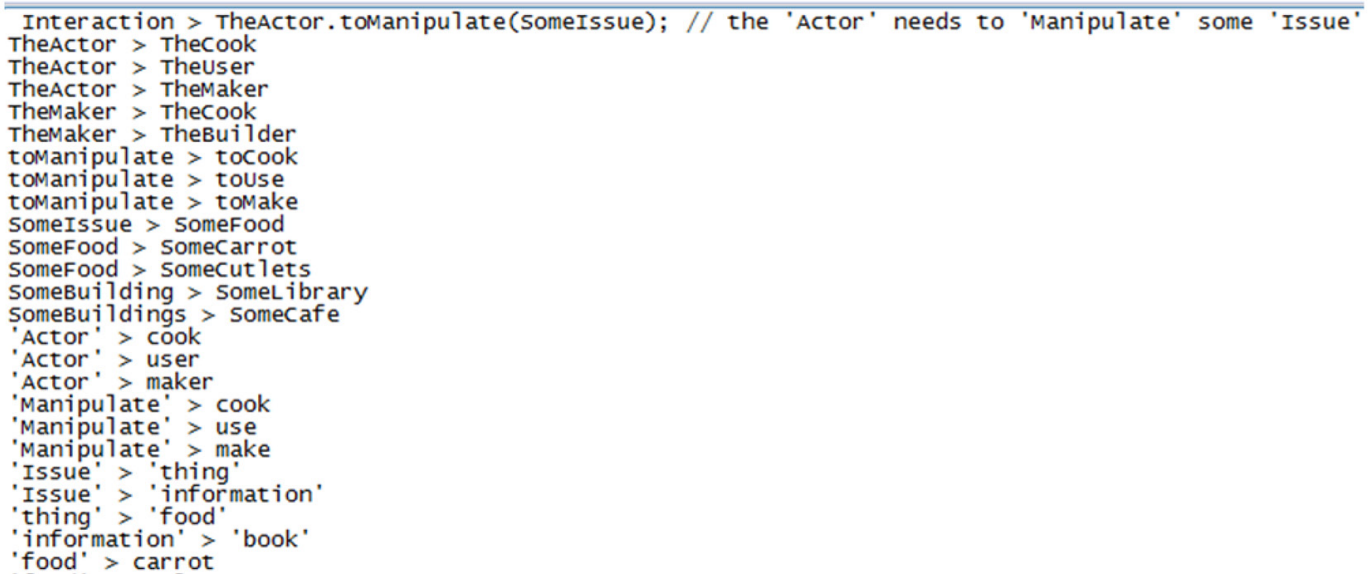

Рис. 1. Порождающая грамматика; TheActor - деятель на игровом поле, toManipulate - алгоритмы, SomeIssue - предмет, над которым будет совершаться манипуляция [2, 3]

Fig. 1. Generative grammar; TheActor - an actor on the field, toManipulate - algorithms, SomeIssue - an object to be manipulated $[2,3]$

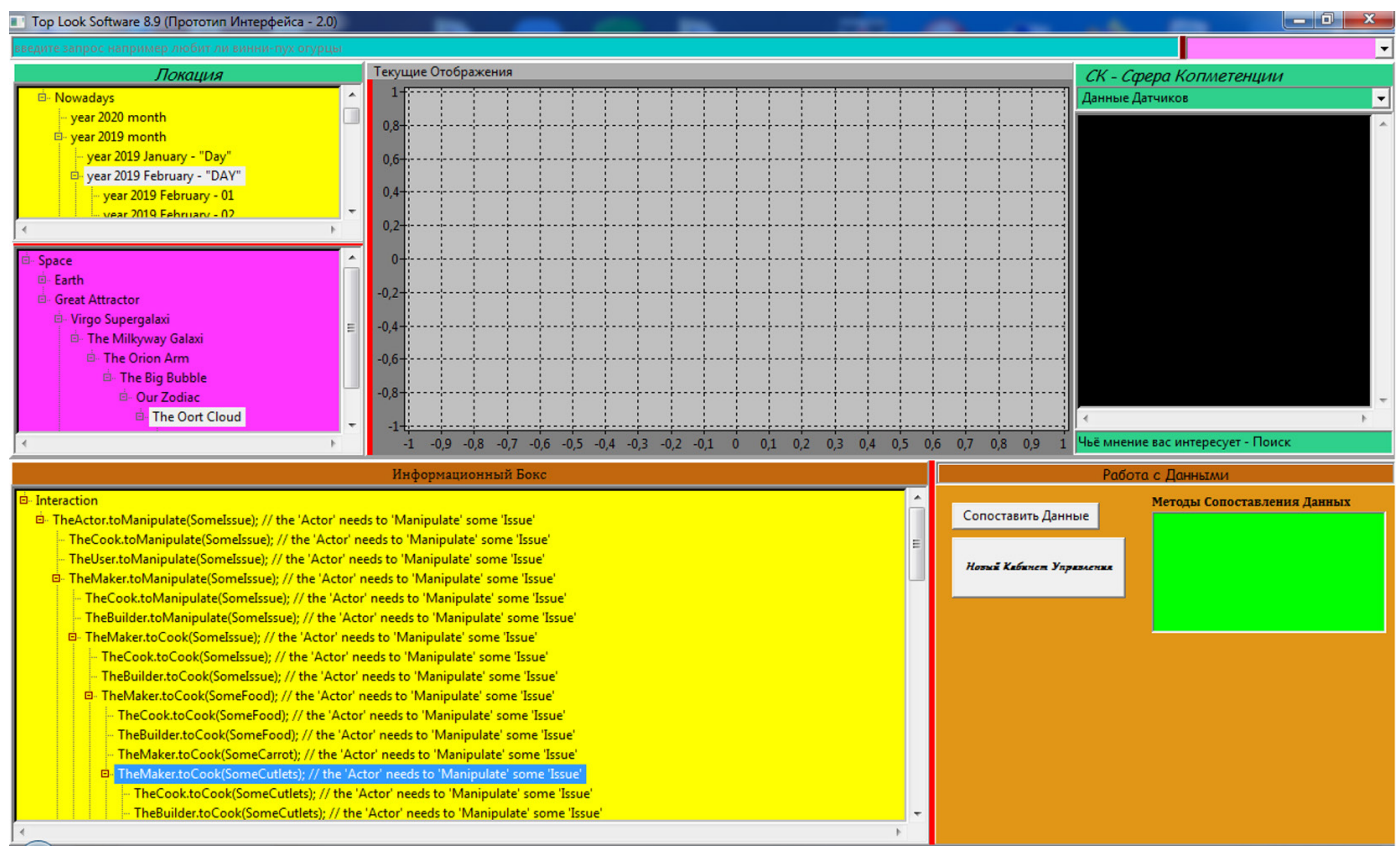

Рис. 2. Результат

Fig. 2. The result 
семантико-прагматической онтологии. Разработанная система составляет семантические портреты текстов на основе модификации текстокода правилами порождающих грамматик над форматами данных. Под форматом мы понимаем расширение понятия объекта в парадигме ООП, когда выражение Format1..Object1 экспортирует объект 1 в формат 1 для его последующей модификации на основе порождающих грамматик и для использования в теле кода на основе разных форматов и подформатов - пространственном, временном, организационном и др.

Ниже программа генерирует все возможные варианты (рис. 2). Также в программе в графе «Локация» приводится время и место.

Предлагается ввести дополнение в выражения порождающих грамматик. Пусть порождающая грамматика генерирует параллельно текст и код для работы на основе выражений:

TimeFormat..LocationFormat..Actor.Method( $\arg 1, \arg 2, \ldots, \arg \mathrm{N})$,

где TimeFormat - время; LocationFormat - локация или место; Actor - деятель; Method() - действие или набор действий; $\arg 1, \arg 2, \ldots, \arg \mathrm{N}$ - предметы, над которыми выполняется действие.

Рассмотрим возможность применения условия как алгоритм или его часть. Например, начальник геологоразведовательной экспедиции командует: «Установить инвентаризированное замерное оборудование».

В качестве программного кода это будет выглядеть следующим образом:

if (Oborudovaniye.inventarizirovanno $==$ false)

\{

21Century..BolotistayaMestnost..Company.Ekspeditsiya.Enjiner.ustanovit(Oborudovaniye); Oborudovaniye.inventarizirovanno $=$ true;

21Century..BolotistayaMestnost..Company.Ekspeditsiya.Enjiner.dolojit(«Текущее оборудование установмено»);

\}

else //после else идет вариант, когАа оборудование уже инвентаризировано -

\{

21Century..BolotistayaMestnost..Company.Ekspeditsiya.Enjiner.dolojit(«Текущеe оборудование уже инвентаризировано»);

\}

..

return 0 ;

Проблема подобной структуры в том, что форматов времени и локаций множество. Поэтому необходимо ввести понятие разбивочной категориальной сетки. Это совокупность значений, которые может принимать формат.

Например, формат зимы включает в себя декабрь, январь, февраль и никак не май, июнь, июль и т. д. Формат XX века включает в себя 1900-1999-е годы и никак не другие. Однако формат декабря может включать в себя любой год.

Что касается локации, то, например, формат Евразии включает в себя такие страны, как Россия, Испания, Польша и т. д., но никак не Канаду. 
Каждый ход всех порождающих грамматик синхронизирован со временем. Каждый ход над транслесом можно сделать с передвижкой маркера настоящего на дереве времени на позицию «Следующий». Маркер можно передвинуть на минуту, час или несколько часов.

Объединив все деревья с помощью транссвязей, можно смоделировать поведение людей и получившуюся модель использовать для предсказания событий (например, результат масштабной работы).

\section{Алгоритм эволюционно оправданных экспансий}

Категориальная сетка системы - представление о мире и о системах с их когнитивной и семантической составляющей.

С точки зрения заявляемого подхода у любой системы есть метацель - благополучие; эта метацель может модифицироваться, переноситься с себя на других и на некое собирательное «мы». Цель элементов категориальной сетки системы оправданной экспансии - найти те форматы, в которых они могут помочь существованию, выживанию, благополучию системы и даже ее дальнейшей экспансии в надсистеме. Принципы баланса и сообразности вынуждена в большей или меньшей степени принимать любая система, что до определенной степени смягчает неконструктивные конфликты и дает системе заняться своей базовой целью. Такое описание применимо к любым системам, особенно к социальным, психологическим, информационным, семантическим, 1-, 2-языковым (естественные языки и языки программирования соответственно), маркетологическим и экономическим системам.

Пусть некто хочет купить окна. Подбор нужных окон начинается в сети Интернет. Поиск ведется как и на сайтах, так и по рекламным объявлениям. В зависимости от того, какие окна нужны потенциальному покупателю предлагаются рекламные объявления и сайты.

Задача рекламных агентств - сделать так, чтобы каждый покупатель нашел то, что ему нужно.

Тот, кто покупает окна, заботится о благополучии семьи (покупка таких окон, чтобы не было продувов). Те, кто занимаются рекламой, заботятся о благополучии покупателей (чтобы покупатели как можно быстрее нашли то, что нужно), организаций-исполнителей, магазинов (чтобы организации нашли своих покупателей и не обанкротились) и своего рекламного агентства.

Три стороны: организация по изготовлению окон, рекламное агентство и покупатель. Какой бы формат этих сторон не был активен - субъекты нацелены на благополучие себя или других субъектов.

\section{Заключение}

В работе вводится новое понятие «транслес» (trans-forest). Это совокупность деревьев, связанных дополнительно: дерево форматов, дерево (иерархия) понятий, иерархия времени, а также просубъектный уровень некой материальной подложки субъектов («силы природы») и иррационального субъекта, аппроксимируемого в модели как граф модели всего мира, усвоенного некой умозрительной, предполагаемой нейросетью субъекта.

Субъекты и «силы» являются на игровом поле транслеса источниками ходов на основе правил порождающих грамматик Монтегю. Каждый ход над транслесом можно сделать с передвижкой маркера настоящего на дереве времени на позицию «Следующий». 
Дерево форматов определяет то, какой субъект сделает следующий ход или как субъект будет поступать в каких-либо ситуациях на постоянной основе. Для того чтобы приблизить модель к реальности, существуют транссвязи между деревьями и их разными уровнями.

Также предложенная модель поддерживает алгоритм эволюционно оправданных экспансий, цель которого обеспечение благополучия для самого субъекта и других субъектов. Субъект осуществляет эту цель через наиболее подходящие форматы.

Модель предназначена для моделирования геологических, учебных, языковых IT-маркетинговых и иных ситуаций с точки зрения теории графов и теории игр. В основном предложенная модель направлена на предсказание поведения людей, объяснение выбора людей и предсказание следующего выбора в области геологии и маркетинга.

\section{Список литературы / References}

[1] Montague R. Formal philosophy: Selected papers. New Haven-London: Yale University Press, 1974, 369.

[2] Личаргин Д.В. Порождение дерева состояний на основе порождающих грамматик над деревьями строк. Сибирскийжурнал науки итехнологий, 2010, 1,57-58 [Lichargin D. V. Generating a state tree based on generating grammatic over row trees. Siberian Journal of Science and Technology, 2010, 1, 57-58 (in Russian)].

[3] Сафонов К.В., Личаргин Д.В. Разработка векторизованной семантической классификации над словами и понятиями естественного языка. Сибирский журнал науки и технологий, 2009, 4, 33-37 [Safonov K. V., Lichargin D. V. Development of a vectorized semantic classification cations over words and concepts of natural language. Siberian Journal of Science and Technology, 2009, 4, 33-37 (in Russian)]. 